\title{
Research and Innovation in Society: Contextualizing a Society Touch in the Academic Block in Tanzania
}

\author{
Tibuhinda Ngonzi* ${ }^{*} \quad$ Andrew Jisaba \\ Department of Accountancy and Finance, St. Augustine University of Tanzania, P.O.Box 307 Mwanza, \\ Tanzania
}

\begin{abstract}
In the triad of academic and specialized research institutions, business, and society blocks, the academic and specialized research institutions domain is naturally expected to be the leader or the principal producers in research and innovation for development (R\&I for D). The remaining business and society entities on the other hand are expected to be the target consumers of the products. For production to happen however, the producers need resources, incentives and motivations as factor inputs. The factors may originate in intra-domains for the respective domain's own use of end results such as it is for business organizations, or across domains for mutual benefits. In turn, the origination of the motives and incentives play a role in defining the relevance of the R\&I products such as the emergence of appropriate research for appropriate innovations. It is in the observations of this paper that overtime, R\&I in Tanzania is becoming undermined by the decline in the cross dimensional flow, specifically the academic (universities) versus society flow. In fact, apart from the specialized institutions, the academics member of the producer block is increasingly becoming too specialized and servicing its own motives in comparison to addressing societal needs. In this paper, we theoretically challenge the phenomenon and use the functional perspectives of the Triple helix model (THM) of university-industry-government cooperation to suggest for innovative education in enhancement of cross border interactions between university and society.
\end{abstract}

Keywords: Key words: Research \& Innovation, Appropriate Research \& Innovations, Triple Helix Model.

DOI: $10.7176 / \mathrm{JEP} / 10-22-11$

Publication date: August $31^{\text {st }} 2019$

\section{Introduction}

In the general terms, this paper conceptualizes innovation as the generation and adoption of new concepts, the definition upheld in a wide range of literature such as Harryson \& Kliknaite (2008, p. 2) "the ability of organizations to adopt new ideas, processes or products"; or Edquist \& Hommen $(1999$, p. 65) who express it as a learning process by which "new knowledge is produced or existing elements of knowledge are combined in new ways". As such, the construct involves creativity, learning, and the objects of creation and learning (Ngonzi, 2015, p. 7).

Innovations are a prime factor for development and cultural evolution. Innovations, development and culture evolve together. Any development stage determines the trajectory of innovations. In turn, for any innovations to be meaningful they have to be relevant to development itself. Institutions of learning are traditionally accepted as the potential sources of innovations and innovative ideas (Altbach, 2013; Eun, Lee, \& Wu, 2006).

According to this paper, the emergence of R\&I in any dimension: academic, industry or society; the flow of innovations across dimensions for implementation; and the emergence of innovation complementaries (IC) in the host dimensions are essential factors for R\&I for development to thrive. We discuss each factor in turn elsewhere in the text.

The main concern of this paper lays in the need for innovative education in the sphere of academics (or universities to be precise). Universities are principally perceived as the key institution in the processes of knowledge creation involving research and innovations (Machumu \& Kisanga, 2014). We express the concern in a form of problem scenarios as stated here under.

\section{The Problem \\ Scenario 1}

It is a common practice for universities to conduct tracer studies in the industry, being the main recipient of their outputs, in order to identify skills requirements in that dimension. The objective is to align skills production in universities with skills requirements in the industry (Bennin, Amoako, \& Ebenezer, 2012; Egesah \& Wahome, 2014). However, the outcomes of such studies have been sometimes frustrating. The actors encounter more complaints than satisfaction. The industry claims of graduates lacking, among other things, problem solving skills, practical skills, practical computer skills, and creativity (Bolaane, Chuma, Toteng, \& Molwane, 2010; Machumu \& Kisanga, 2014; Manda \& Matidza, 2016). To this, some scholars (Bennin et al., 2012, p. 41) have suggested that institutions of higher learning should focus on "producing graduates that are needed by the industry instead of trying to sell graduates just as they have produced them without the involvement of industry". 


\section{Scenario 2}

The instances of universities marketing innovations generated by them as new ideas for the industry and society are scarce on records. Essentially, universities do not seem to have a noted leading role in innovations. Here there is a danger of universities being appreciated for outdated knowledge (see for example Bolaane, Chuma, Toteng, \& Molwane, 2010).

\section{Scenario 3}

Context specific examples exist, where universities survive amidst problems they are not aware of in their surrounding communities. Either they live as super sub-communities in large communities, or they lack sensitive academic sensory organs to see, hear and sniff (experiential observation of the authors).

\subsection{Problem analysis}

In the analysis, the three presented scenarios can be attributed to: (1) universities' lack of exposure to industry realities related to the learner's fields of studies; (2) Technology enhanced higher velocity of knowledge evolution in practice (industry) than it is in academics (universities); and (3) Universities operating too much confined to curricular that is not accommodative of inputs from the environment respectively. In this third observation for instance, universities do not have opportunities to create inventories of, say existing problems in their surroundings, and the solutions in the pipelines, say existing in plans in government ministries, departments and agencies (MDAs).

\subsection{The Claim}

The scenarios like those presented above will remain for too long to the detriment of development, unless we define specific parameters through which to work to implement interactions between universities and their surroundings. This is especially so in the context of developing economies where there is a big knowledge gap between universities and societies. We use the constructs of the Triple Helix model to conceptualize the enhancements for such interactions.

\subsection{The Triple Helix model}

Research and Innovation is about development. As such, the mechanisms to allow for the flow of knowledge among the blocks of creation and utilization of R\&I products are critically essential. The Triple Helix model (THM) is a conceptual tool applicable in devising such flows of knowledge. The model is defined by its proponents Leydesdorff and Etzkowitz in an institutional setting, and theoretical constructs (Leydesdorff, 2012; Leydesdorff \& Etzkowitz, 1998).

In an institutional setting, scholars describe the model as a construct of strategic relationships between three independent helices: universities, industry and the governments, as the key pillars in innovation processes. In its theoretical construction, the model is based on the triplex as autonomous institutional spheres, and the interrelationships among them informing institutional arrangements for the relations to materials generated and the provisional interactions. Conceptually, the model is, according to Etzkowitz and Ranga (n.d.), as a specification of the "institutional and social formats for the production, transfer and application of knowledge" (p 5).

Suffice for the scope of this paper at the moment, to state that in literature there are three classes of the model: 'a statist model of government controlling academia and industry; a laissez-faire model, with industry, academia, and government separate from each other but interacting only moderately across strong boundaries; and the hybrid form in which each institutional sphere keeps its own distinctive characteristics and at the same time also assumes the roles of the others (Razak \& White, 2015). The reader is referred to the cited and similar resources for a detailed classification of the classes. Since its inception in the 1990s, the model is known to have achieved a considerable attraction around the globe using the dedicated conferences such as the $2^{\text {nd }}$ International 'Triple Helix' conference on university-industry-government relations at the State University of New York in 1998 (Leydesdorff \& Etzkowitz, 1998), and the Triple Helix research group ("The Triple Helix concept | Triple Helix Research Group," n.d.) as living evidences.

In the reporting of Leydersdorff and Etzkowitz on the proceedings of the $2^{\text {nd }}$ International 'Triple Helix' conference on university-industry-government relations (Leydesdorff \& Etzkowitz, 1998), the triple helix construct was theoretically espoused in three forms: the triple helix I, II and III (TH I, II and III). TH I conceptualize the helices as the principal institutions in the innovation processes as stated before (universities, industry and government). In this form the helices exist with defended boundaries around their core activities. The interactions across boundaries happen through special arrangements, such as industrial liaison, technology transfer, and contractual agreements.

In TH II the helices are functionally referenced as different communication systems consisting of 'the operation of markets', 'technological innovations' and 'control at the interfaces'(Leydesdorff \& Etzkowitz, 1998).

TH III is an extension to the first mode in that, the institutions can create zones of overlap beyond their core activities such as "universities creating an industrial penumbra, or performing a quasi-governmental role as a 
regional or local innovation organizer" (Leydesdorff \& Etzkowitz, 1998, p. 197). With industrial penumbra it refers to universities, or their academic staff indulging in business to apply their innovations like the scenarios in China (Cai, 2014; Harryson \& Kliknaite, 2008), and America (Harryson \& Kliknaite, 2008). The TH I, II and III are summarized in Figure 1 below.

An overlap of roles in the triplex of institutions Quasi representations

Triple Helix III

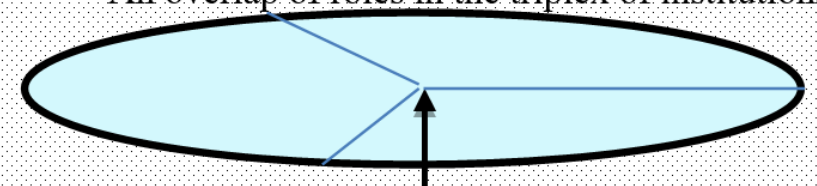

Triple Helix II

A triplex of Communi ative overlaps OM-TI-Cl on the platform of

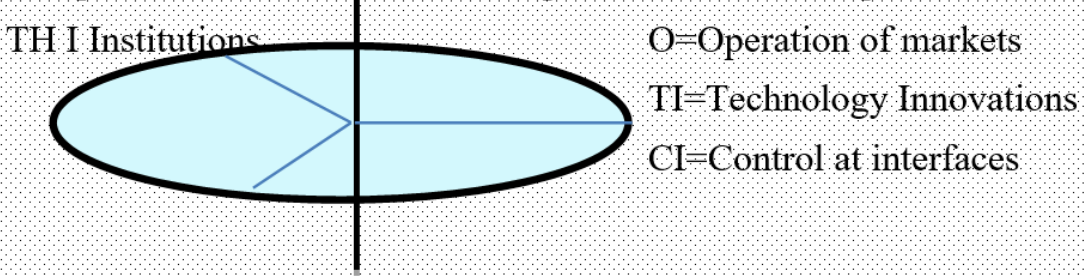

A triplex of Institutions U-I-G with specialized functions

Triple Helix I

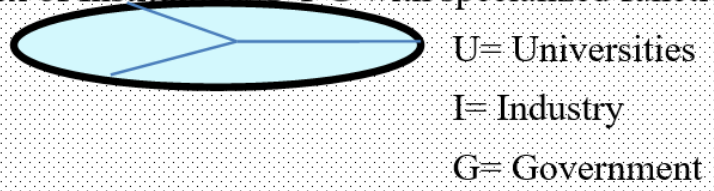

Figure 1Theoretical evolution of the Triple Helix Model (Adopted from Leydesdorff \& Etzkowitz, 1998)

We utilize the concepts of cross boundary interaction through contractual agreements of TH I, and the 'quasigovernmental role as a regional or local innovation organizer' of TH III to tackle issues of academic (universities) distance from societal problems. We present the paper's opinion that, with its inherent capacities in the conception of THM where the government can arrange to sponsor innovations, organize for innovations, or enhance interactions on contractual arrangements through policy tools. The institution stands to benefit universities that uphold innovative education. A specific case is where a university wishes to interact with society for mutual benefits.

In our understanding however, the THM has to be used with caution when applied to different contexts. In the advanced economies for instance, the roles of the government in the triad can be easily identified as the developer of policies on innovations in communities and provider of resources in some instances; the industry is deep and advanced with plenty of resources and expertise, while the research capacity of universities is high and well furnished.

For the developing countries the contrary define the facts. In reference to that for instance, the TH II and III identified forms would seem too advanced.

To contextualize the phenomenon, we first present the situations underlying the emergence of innovations, and how can cross boundary innovations thrive in other dimensions. Thereafter we look at the special case of universities versus society in applied TH concepts to facilitate R\&I for societal problem solving.

\section{Sources of innovation}

Two sources of innovations are possible in any dimension of the academics, industry and society blocks: an external source and an internal source. When the innovation originates externally, the host dimension must have capabilities to integrate the innovation in its functional structures. That is, the dimension must have integrative or adaptive capabilities. When the origination of innovation comes from within, the host dimension must have capabilities to apply the innovation for different functionings (i.e., must have functional capabilities in itself). With regard to the question at hand, when the society is the context, the same must have such characteristics.

\subsection{The emergence of $R \& I$ for Development}

Resources, incentives and motivations are crucially important as the catalysts for the emergence of ideas and research in the domains of academics, business and society. Where capacity prevails, big companies in business establish their own units for the R\&I for development. They have the resources: money, professionals and facilities. The motive is to sustain their competitive edge; while the practicing professionals have incentive packages within policy reword frameworks. Their products are not open but proprietary technology.

R\&I in the academics block is differently driven. The motives are, to a greater extent, centred on the reward framework such as promotion through publications (Kongolo, 2019). The resources are meagre. It is easy in such 
circumstances for the actors in that space to seek personal gains through personal means, in the end not delivering service to side dimensions. It is in special setups that resources flow to universities in some places of the world. For instance, the Japanese government fund research universities to purposely create centres of excellence, China provide funding with the aim of creating world-class institutions, while in places such as the US, UK and Germany the purpose is to maintain sustained standards (Altbach, 2013). In other cases, research in universities is carried out in collaboration with, or sponsored by funding institutional bodies.

The society block in the context of developing economies is grossly dependent on R\&I products of other blocks. Reported in this block are rudimentary instances of innovation. Being less organized in purpose than the other blocks, motivations for any endeavor exist at an individual level, driven by self-initiatives. Figure 2 conceptualizes the phenomenon schematically.

\section{Universities}

(have innovation capacity but need resources)

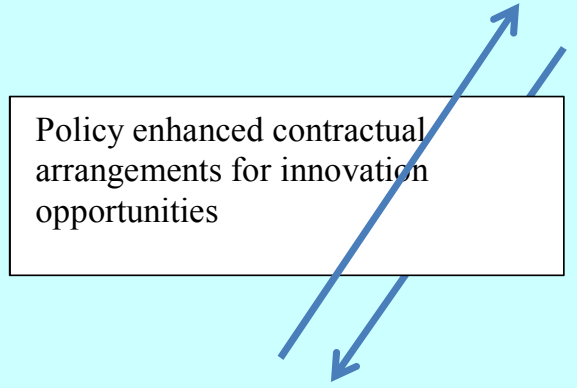

Society

(low innovation capacity but a focus for innovations to respond to its problems)

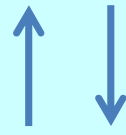

Government

(Facilitate innovation capacity for problem solving in societv)

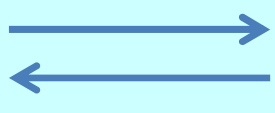

Industry

(High on resources, moderate innovation capacity but internal focus to respond to its market needs)

Figure 2 The Innovation capabilities in blocks and interaction

The government leads innovations through specialized research institutions for medical, agriculture, wildlife, fisheries, etc. purposes. The examples in Tanzania include the National Institute for Medical Research (NIMR), Tropical Pesticides Research Institute (TPRI-Arusha), Tanzania Wildlife Research Institute (TWRI) respectively etc. (Commonwealth, n.d.). In addition to playing a direct role in R\&I for D through specialized institutions, the government has a facilitation role for other arrangements regarding universities and society.

Evident in the circumstances where universities turn to themselves is the loss of societal touch at the cost of development. To rescue the situation, we view a need for special and purposeful arrangements to engage universities and society for beneficial interactions. Universities should innovatively create conditions through educational mechanisms for them to be aware of their communities. It is observed in the foreword of the OECDs' Workshop on innovation for social challenges that "...the social-dimension is no longer peripheral to science, technology and innovation (STI), but a central factor for driving research funding decisions and shaping outcomes" (OECD, 2011, p. 3). Universities should understand that innovations for societal problem solving are more likely to be fostered from the society than the journals and books. This is possible through engagement with the society to enable the creation of academic/society shared development values.

It is important however, that any innovation lead initiatives in the context of universities in undeveloped societies must have a focus on enhancing for three basic factors for R\&I for D, VIZ: (1) leading to context specific appropriate innovations; (2) the cross boundary flow of innovations; and (3) enhancement for innovation complementaries in recipient blocks. We briefly clarify on each one next.

\subsection{Context specific appropriate innovations}

The instruments for knowledge creation are basic research, applied research, and innovations. To these we add appropriate research, which we define as the type of applied research, specifically initiated and executed for a specific societal problem as identified from the society in context. Societies need appropriate research for appropriate innovations, in addition to the traditional basic and applied types of research. Appropriate innovations associate with problems of human life, that the innovation is designed to help to solve. It has emphasis on its application. To make such innovations practical, they must incorporate rules of operations; that is moving from 
knowing what the case is, to knowing what to do about or with it.

\subsection{The flow of innovations across dimensions}

The flow of innovations across dimensions is too broad to be exhaustively presented within the scope of a paper like this. The phenomenon has the pro and limiting factors, resulting as the consequences of the conditions and policies existing or completely missing within and across dimensions. Scholars have addressed the issue of cross dimension innovations in a number of ways. The triple helix model (Leydesdorff \& Etzkowitz, 1998) express university-industry-government relations shedding light on issues of institutional interaction through 'industrial liaisons', 'technology transfer' and 'contract modalities' on one hand; 'operation of markets', 'technological innovations' and 'control at the interfaces' as the communication network functions perspective of triple helix on the other; and the performance of cross border roles among institutions (Leydesdorff \& Etzkowitz, 1998) (see the description of THM on page 4). The authors also explicate the presence of a window for universities to create 'industrial penumbras' in this perspective.

Harryson and Kliknaite (2008) explore the benefits of innovation advancement in industries that are achieved from technology based universities in their vicinities. Among them is the 'leaning alliances', a benefit explained as an outcome of collaboration arrangements. Though the arrangements, universities indulge in basic innovations research, while supporting the processes by which the industry assimilate the outcomes.

We develop a hypothesis here that, given special arrangements, universities can build working frameworks to make the societies around them experience their impacts. On this basis, we pose questions like; given the fact that there are universities in the surroundings offering first degrees in civil engineering for instance, do they have an inventory of high level engineering works such as roads construction taking place in their vicinity (in the city of Mwanza at least)? Are they aware of the geological challenges, weather bottlenecks, social factors (theft) etc. that are being faced and how they are being overcome?

A similar question is on whether any university has on its records, the instances by which it has reached out to expedite solutions to social and business problems in their vicinities as leaders of innovations, apart from chasing the industry to know what they want/expect from the universities around them?

It is through such self-critiquing that problem driven R\&I can emerge in universities as a lead to applied and appropriate research. The issue then remains to be how to motivate for that to happen.

\subsection{The importance of innovation complementaries (ICs)}

Given the necessary resources, universities can utilize their high level skills and expertise to lead to scientific breakthroughs through basic research and innovations. These are to be later complemented with applied innovations in adaptation for production purposes. Innovation complementaries (ICs) are the innovations such as process innovation, that develop in firms or sectors with complementary relationships with the innovation's sector of origin.

ICs are very important in the diffusion of any new innovation, as they lead to sharpening the relevance of that innovation in application and sustainability, in the due course providing a feedback to its originators for further improvements for adoption where necessary.

A challenge to this is how well societies, especially in developing economies further challenged with ill education and poverty are capable of developing ICs. This is from the understanding that the creation of ICs is a function of innovation capabilities in the domains' functionings, which include the availability of complementary investments (resources) on the other hand (Robeyns, 2005; Zheng \& Stahl, 2011). The questions like this cannot be left alone in a setting like the THM. In that model, at least role playing can promise something, say instituting some provisions at the interface to start with, universities taking initiatives to act as push agents, or other kinds of efforts. Worth citing is the example of JUMEME project in which SAUT is a shareholder (rp-Global, n.d.). This is a kind of interface through which the university and the context society in the Lake Victoria islands of Bwisya and Ukara stand to benefit from as an innovation gateway. The Figure 3 below is a diagrammatical representation of the association of the factors discussed in this section. 


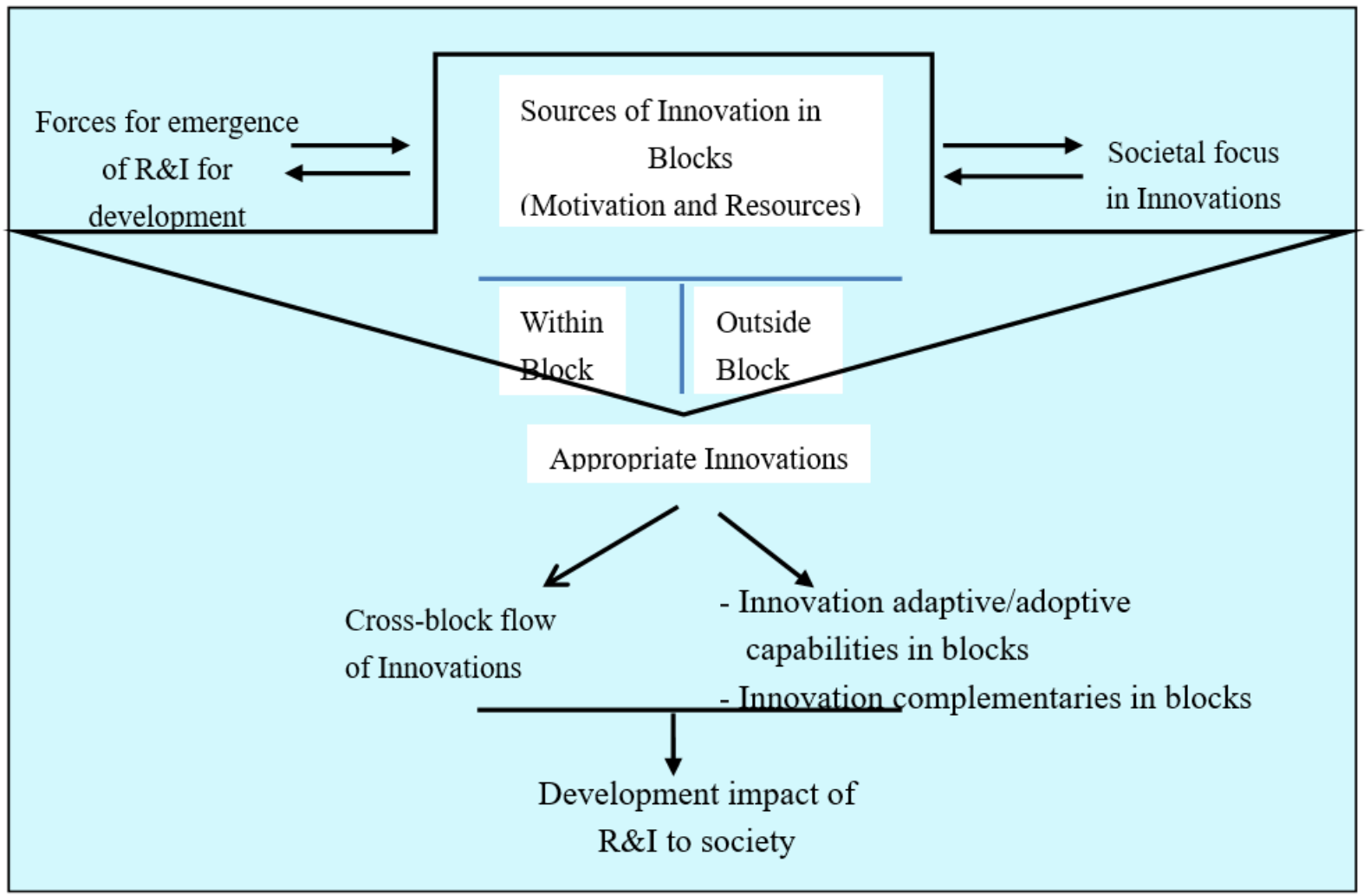

Figure 4 The association of the factors for appropriate innovations in societies

\section{Innovative Education as a key to academic-society touch establishment}

Education in developing countries faces two major antagonistic challenges. One is that it tends to be driven by knowledge and frameworks that are imported from advanced countries. Education processes in developing countries have to be re-engineered to fit local conditions through applied research for applied innovations. The second dwells on the question of making education accommodate social problems solving machinery in the immediate societies through innovations, at the same time enhancing the respective societies to adopt innovations with ICs. The task of addressing these issues needs innovative approaches in education from the traditional ways. For instance, entrepreneurship is not how it is learnt in class, but how it is practiced out there. To learn to become entrepreneurs, one must learn from those out there. If that is the case, why don't we in universities go out and learn from the entrepreneurs? In the other words, it is about enhancing university learners with local conditions, in the way creating conditions for the emergence of appropriate innovations.

\subsection{Operationalizing THM with innovative Education}

There are two general observations in the lenses of the THM in this paper related to the universities-industrygovernment institutions in the countries characterized by low technology level. One is that there are no elaborate and codified relations among the THM institutions. Following on one is the second observation that there is a lack of institutional arrangements necessary to operationalize specific mutual benefit interactions among institutions for instance. In this paper we focus on the use of the key elements of the THM that are applied to specify relations in the TH I coded as 'industrial liaison' (herein after applied as 'societal liaison') and 'contractual' arrangements. We leave the 'technology transfer' pending for the moment. These are potential in the facilitation for academic (universities) and societal interactions. The academics block stands to benefit from the factors in the intermediation of the government helix. The government here is looked upon to facilitate the generation of policy tools for the interactions. The academics should utilize the interactions to cultivate for drawing inputs from the society to create ambiance for innovations for societies in a two way stroke. The first stroke is where universities take to learn of the problems, and from the solutions if any from ex-society sources. By this we mean learning from say the construction projects being executed by foreign companies. In enhancing university learners with local conditions, universities have to embark on frameworks such as the triple helix model. The following example serves to clarify on the issue.

Overtime, the country of Tanzania has used foreign companies in a number of civil works, specifically roads and high level buildings construction. The question is, what skills do these foreign companies leave for our university repositories after the projects? It is thus in our opinion that, if the country could methodologically apply 
the THM, the project work contracts involved could harbor provisions for university students around to participate even under voluntary unpaid labour arrangements for them to learn. We believe, for instance, that our Civil Engineering learners at St. Augustine University of Tanzania (SAUT) could benefit from the constructions involving roads going through challenging terrains such as the Sabasaba-Busweru and the Makongoro JunctionMwaloni projects in Ilemela Munispality in Mwanza City respectively (Project no. P148974 (World-Bank, n.d.)) among others. In this spirit, the university could come up with innovative ideas such as keeping an inventory of engineering works underway in the locality, or devising notification means for getting informed whenever new undertakings are in the pipeline, referring to the communication construct of TH II.

It the broader terms, universities in the developing countries need to engage societies both ways: to take innovations to society, and seek learning opportunities from it. In essence, university-society interaction should be the easier way to discerning and generating solutions to society problems.

\section{Conclusions}

In this paper, the issue was to expose the developing gap between universities as centres of innovations and the societies which are the assimilation centres for the innovations. The paper espoused the gap in failure of universities to focus research for innovation towards societal needs, while attributing it to the differences inherent in the nature of the motives driving innovations in universities, especially where resources for research are meagre such as private universities. With own resources, professionals address personal motives in turn. At the same time, the discussion noted that societies, especially in developing countries have no capacity to develop the necessary innovation complementaries and investments necessary in the innovation assimilation processes.

However, it was suggested in the operationalization of the triple helix model that, innovative education can utilize the capacity of governments in the model to come up with academic-society interaction arrangements, through which the academic block at large can tap from, and develop innovations to societies.

\section{References}

Altbach, P. G. (2013). Advancing the national and global knowledge economy: The role of research universities in developing countries. Studies in Higher Education, 38(3), 316-330. https://doi.org/10.1080/03075079.2013.773222

Bennin, E. W., Amoako, G. K., \& Ebenezer, E. E. S. (2012). Keeping Products of Higher Educational Institutions (HEIs) of Relevance to the Industry - A Reason to Stay in Touch with Alumni. Journal of Education and Practice, 3(5), 40-46.

Bolaane, B., Chuma, J. M., Toteng, B., \& Molwane, O. . (2010). Tracer studies on the employment outcomes of the vocational training graduates. Gaborone.

Cai, Y. (2014). Implementing the Triple Helix model in a non-Western context: an institutional logics perspective. Triple Helix, 1(1), 1. https://doi.org/10.1186/s40604-014-0001-2

Commonwealth. (n.d.). Research Institutes in United Republic of Tanzania. Retrieved June 24, 2019, from http://www.commonwealthofnations.org/sectorsunited_republic_of_tanzania/education/research_institutes/

Edquist, C., \& Hommen, L. (1999). Systems of innovation: theory and policy for the demand side. Technology in Society, 21(1), 63-79.

Egesah, O., \& Wahome, M. (2014). University graduate tracer studies ( UNITRACE ): Methodological lessons and utilization of selected results in Kenya. JOURNAL OF INTERNATIONAL ACADEMIC RESEARCH FOR MULTIDISCIPLINARY, 3(8), 305-325.

Eun, J.-H., Lee, K., \& Wu, G. (2006). Explaining the "University-run enterprises" in China: A theoretical framework for university-industry relationship in developing countries and its application to China. Research Policy, 35, 1329-1346.

Harryson, S., \& Kliknaite, S. (2008). How technology - based university research drives innovation in Europe and China. Journal of Technology Management in China, 3(1), 12-46. https://doi.org/10.1108/17468770810851485

Kongolo, M. (2019). Motivating factors for Academic Staff to conduct and increase research output at University. International Journal of Social Sciences and Management Studies, 2(4 July-August), 53-66.

Leydesdorff, L. (2012). The Knowledge-Based Economy and the Triple Helix Model. Annual Review of Information Science and Technology, 44(2010), 367-17. Retrieved from http://arxiv.org/abs/1201.4553

Leydesdorff, L., \& Etzkowitz, H. (1998). The triple helix as a model for innovation studies. Science and Public Policy, 25(3), 195-203. Retrieved from https://academic.oup.com/spp/article-abstract/25/3/195/1630936

Machumu, H. J., \& Kisanga, S. H. (2014). Quality Assurance Practices in Higher Education Institutions: Lesson from Africa. Journal of Education and Practice, 5(16), 144-157.

Manda, M., \& Matidza, I. (2016). A Tracer study of 2011-2015 graduates from the Land Management Programme at Mzuzu University. Journal of Education and Society in Southern Africa, 3(3), 45-67. 
Ngonzi, T. (2015). Theorizing ICT-based Social Innovation on Development in the Context of Developing Countries of Africa. University of Cape Town. Retrieved from https://open.uct.ac.za/handle/11427/20479

OECD. (2011). Fostering Innovation to Address Social Challenges. OECD.

Ranga, M., \& Etzkowitz, H. (n.d.). Triple Helix Systems: An Analytical Framework for Innovation Policy and Practice in the Knowledge Society.

Razak, A. A., \& White, G. R. T. (2015). The Triple Helix model for innovation : A holistic exploration of barriers and enablers. International Journal of Business Performance and Supply Chain Modelling, 7(3), 278-290. https://doi.org/10.1504/IJBPSCM.2015.071600

Robeyns, I. (2005). The capability approach: a theoretical survey. Journal of Human Development, 6(1), 93-117.

rp-Global. (n.d.). 200 MW Solar-Hybrid Mini-Grid Project Under Construction. Retrieved July 13, 2019, from https://www.tanzaniainvest.com/energy/200-mw-solar-hybrid-mini-grid

The Triple Helix concept | Triple Helix Research Group. (n.d.). Retrieved June 10, 2019, from https://riplehelix.stanford.edu/3helix concept

World-Bank. (n.d.). Procurement Notices - Upgrading/rehabilitation Of Makongoro Junction -mwaloni,sabasabakiseke-buswelu And Isamilo-mji Mwema Roads, Andconstruction Of Skip Pads. | The World Bank. Retrieved July 13, 2019, from http://projects.worldbank.org/procurement/noticeoverview?id=OP00048261

Zheng, Y., \& Stahl, B. (2011). Technology, capabilities and critical perspectives: what can critical theory contribute to Sen's capability approach? Ethics and Information Technology. Retrieved from http://link.springer.com.ezproxy.uct.ac.za/article/10.1007/s10676-011-9264-8 